\title{
Amazonian medicinal plants botanical garden of takiwasi center in Peru; a case report of 25 years' hands-on experience
}

\begin{abstract}
I The Center for Drug Addiction Treatment and Research on Traditional Medicines - Takiwasi, is a 25 years' Non-Governmental-Organization (NGO) specialized in the treatment of drug addiction and mental health disorders based on modern psychotherapy and biomedical approach, as well as the use of herbal Traditional Amazonian Medicine (TAM). Part of this latter therapeutic resources are obtained directly from the Medicinal Plants Botanical Garden of the Center, which represents therefore one of the core activity of Takiwasi. This garden currently counts more than 80 medicinal plant species representative of local medical traditions, holding different indication of use including depurative, relaxing and visionary ones. During its 25 years' lifetime, Takiwasi Center has also developed a spin-off natural product pharmaceutical laboratory which is manufacturing herbal medicines for the general public based on the ancestral Amazonian herbal knowledge, following the principles of fair-trade and eco-sustainability and in accord with the national regulation concerning indigenous knowledge protection. The Medicinal Plants Botanical Garden of Takiwasi provide multidisciplinary outputs which include the supply of herbal medicines used in the treatment protocol of the Center, as well as a series of seedlings used within the reforestation programs performed in the Conservation Area named "Cordillera Escalera" located near-by the Center. The garden also serves as an ecological interface, useful to introduce generic or specialized visitors to the fundamentals of TAM. It represents therefore a successful experience of living resource of Amazonian medicinal plant materials and related therapeutic know-how, which merits further attention and support in order to widespread its beneficial effects for the health of humans and nature.
\end{abstract}

Keywords: medicinal plants, botanical garden, traditional Amazonian medicine, drug addiction treatment
Volume 2 Issue 3 - 2018

\author{
Matteo Politi, Fabio Friso \\ Center for Drug Addiction Treatment and Research on \\ Traditional Medicines, Peru
}

Correspondence: Matteo Politi, Center for Drug Addiction Treatment and Research on Traditional Medicines - Takiwasi, Prolongación Alerta 466, Tarapoto, Peru, Tel +39 3477409072, Email matteo.politi@takiwasi.com

Received: November 3, 2017 | Published: May 09, 2018

\section{Introduction}

Takiwasi is a Center for the rehabilitation of drug addicts, mental health treatment and research on traditional medicines located in the city of Tarapoto, in the Peruvian High-Amazon, where it was founded as a Non-Governmental-Organization in 1992 by a group of local and foreign experts including the current Chief Executive Officer, the French physician Jacques Mabit, who was inspired to investigate on Traditional Amazonian Medicine (TAM) during the '80 after a "Doctors Without Borders" experience in Peru. The therapeutic proposal of the Center is based on an innovative protocol, characterized by the combination of conventional psychological and medical therapies and the knowledge and practices of TAM. The protocol is defined by a healing tripod that includes 3 complementary therapeutic workspaces that mutually provide feedback to each other: ${ }^{1}$

i. Coexistence and Ergo-therapy

ii. Psychotherapy

iii. Medicinal plants

Medicinal plants are therefore one of the central axes of the treatment and represent the core elements coming from research on TAM. For this reason, special attention has always been dedicated to the Botanical Garden along the lifetime of Takiwasi Center, which is now counting with more than 80 medicinal plants species, the majority of which are native of the High-Amazon region of Peru; it includes as well a good collection of different orchids, which represent a typical and native botanical family of the region. This garden, which is maintained manually and without the use of any sort of agro-chemicals, serves not only as an interface to introduce visitors to the general concepts of TAM, but also as a source of medicaments used in the therapeutic protocol, and as an outdoor laboratory to grow medicinal species which are used within the re-forestation programs of the Center. Takiwasi Center receives an average of 1000 visitors per year from all over the world, of which 271 were registered in 2016 specifically for the Botanical Garden. These visitors have the chance to learn about its therapeutic practices and have a close look at its infrastructure which includes a 2-hectare park where the Medicinal Plants Botanical Garden take place, embracing also the Headquarter of the Center, the House of Resident Patients, the Natural Product Laboratory specialized in products development from Amazonian medicinal plants, a Library specialized on TAM, and two main Malocas which are traditional Amazonian structures used for communal life and ritual practices including medicinal plant ingestion. Takiwasi owns as well a so-called Botanical Reserve, a detached land of 54 hectares of secondary forest located within the Regional Conservation Area "Cordillera Escalera", managed in conjunction with the Peruvian State. This area has basic infrastructure for receiving patients and researchers, and represents the main target of the re-forestation actions using the medicinal plants grown at the Botanical Garden. 


\section{Case presentation}

During the 25 years' lifetime of Takiwasi Center and its research efforts, it was possible to develop a therapeutic protocol applied to drug addictions and mental disorders based also on the use of herbal TAM. Moreover, several registered phyto-pharmaceutical products for health and personal care inspired by the ancestral knowledge of Amazonian medicine were also developed in collaboration with native communities under the fair-trade and eco-sustainability principles and in compliance with the national rules concerning indigenous knowledge protection and benefit sharing rights. While such phytopharmaceutical products are now prepared by using medicinal plants such as Uña de Gato (Uncaria tomentosa), Pampa Orégano (Lippia alba), Sangre de Grado (Croton licheri), and Copaiba (Copaifera langsdorffii) which are cultivated or collected outside the Center due to the growing market requests, several herbal medicines used in the therapeutic protocol for drug addictions and mental disorders are still prepared by using the fresh plant materials cultivated in the Botanical Garden or grown in the Botanical Reserve. Such herbal medicines can be differentiated according to the following categories of use:

a. Emetic Plants, very useful for detoxification and depurative purposes. Among these we find Rosa Sisa (Tagetes erecta), Yawar Panga (Aristolochia didyma), Azucena (Lilium sp.). Verbena (Verbena sp.), Sauco (Sambucus peruviana)

b. Containment Plants, valuable for maintaining and strengthening the effects of depurative plants on a daily basis, such as Mucu- ra (Petiveria alliacea), Ajo Sacha (Mansoa alliacea), Camalonga (Strychnus $s p$.).

c. Master Plants, including Visionary Plants that can provide psychotropic experiences such as Ayahuasca (Banisteriopsis caapi), Chacruna (Psychotria viridis), Tobacco (Nicotiana rustica), Coca (Erythroxylum coca), and Diet Plants, the ingestion of which is ritualized following a series of physical and sensorial restrictions, and occur in isolation for a certain period.

d. Ritual Bath Plants, aromatic and relaxing ones used for energetic cleaning. This is a necessary step before the Ayahuasca session and a useful tool of the treatment protocol, therefore constantly applied during the rehabilitation period. The used plants include Toé (Brugmansia suaveolens), Hierba Luisa (Cymbopogon citratus), Ruda (Ruta graveolens).

The concept of "Master Plants" is largely widespread within $\mathrm{TAM}^{2}$ and refers to the fact that such plants holds a spirit that can teach and generate knowledge through dreams, visions, perceptions and intuitions. Within the therapeutic protocol of Takiwasi Center, Diet Plants have to be consumed in isolation and following specific restrictions, in a condition commonly referred to as "Dieta", which represents one of deepest therapeutic tool of TAM. ${ }^{3}$ Table 1 shows a list of some of the main Diet Plants currently growing in the Botanical Garden of Takiwasi Center and commonly used in the "Dieta", with their main properties. ${ }^{4}$

Table I Main diet plants currently growing in the botanical garden of takiwasi center (in alphabetical order)

\begin{tabular}{|c|c|c|c|}
\hline Plant & Scientific Name & Physical / Psychic Effects & Teaching \\
\hline Ajo Sacha & Mansoa Alliacea & $\begin{array}{l}\text { Sensation of body heat. Headache. } \\
\text { Discernment, mental clarification. Ability to decide. Stimulate } \\
\text { the defenses. Luminous dreams. }\end{array}$ & $\begin{array}{l}\text { Ability to choose and decide. Strengthens } \\
\text { the will. }\end{array}$ \\
\hline Bobinsana & Calliandra angustifolia & $\begin{array}{l}\text { Musculoskeletal pain, dizziness. } \\
\text { Calms, causes reflections, smooth feelings. Capacity to be } \\
\text { flexible. }\end{array}$ & $\begin{array}{l}\text { Rooting, affective communication, } \\
\text { openness of heart. }\end{array}$ \\
\hline Chiric sanango & Brunfelsia grandiflora & $\begin{array}{l}\text { Initial sensation of intense cold, chills then heat and } \\
\text { dizziness. Weakness and pain. Tingling lips and extremities. } \\
\text { Very strong dreams that reveal our concerns and fears. It } \\
\text { takes out fears, affective coldness, shyness, and excessive } \\
\text { introversion. }\end{array}$ & $\begin{array}{l}\text { Increase self-confidence, loss of fear. It } \\
\text { opens oneself to the others and to the } \\
\text { outside world. }\end{array}$ \\
\hline Uchusanango & $\begin{array}{l}\text { Tabernaemontana } \\
\text { sananho }\end{array}$ & $\begin{array}{l}\text { Heat, dizziness, weakness, vomiting and occasional diarrhea. } \\
\text { Very marked physical effects. Sexual excitation. Sight } \\
\text { disorders. } \\
\text { It tones, affirms will, correction of errors, making specific } \\
\text { plans for the future. Feeling of eliminating negative thoughts } \\
\text { (purification by fire), irritability. Awakening of the libido. }\end{array}$ & $\begin{array}{l}\text { Righteousness of acts, decision-making, } \\
\text { especially in concrete terms, how to be } \\
\text { more executive, more rigorous. }\end{array}$ \\
\hline $\begin{array}{l}\text { Ushpawasha } \\
\text { sanango }\end{array}$ & $\begin{array}{l}\text { Tabernaemontana } \\
\text { undulata }\end{array}$ & $\begin{array}{l}\text { Somnolence, slight dizziness. } \\
\text { Increased dream activity. Extended perception of nature, } \\
\text { hypersensitivity. Affective release. Empowers affective } \\
\text { memory. }\end{array}$ & $\begin{array}{l}\text { Metabolisms of memories of emotional } \\
\text { importance. Catharsis and emotional } \\
\text { balance. This plant is called the "memory } \\
\text { of the heart". }\end{array}$ \\
\hline
\end{tabular}




\section{Discussion}

After 25 years of activities, the Takiwasi Center Botanical Garden proves to be a successful example of integration between traditional and modern practices related to the Amazonian medicine. On one hand, plant species were selected and cultivated on the basis of their traditional use and are still treated, recollected, processed and administered following the general principles of TAM, which include a close relationship with the plant world based on the belief that plants are living organism to which it is possible to interact. ${ }^{5,6}$ On the other hand, they are part of the Takiwasi therapeutic protocol, which represent an innovative approach to treat diseases which belong mostly to the modern culture, i.e. addiction to substances and mental health disorders including depression. In fact, the Ayahuasca brew, one of the herbal TAM used in the protocol, is recognized by the scientific community as a promising drug "against various diseases of civilization". ${ }^{7}$ Moreover, the multidisciplinary nature of Takiwasi Center allows its Medicinal Plants Botanical Garden to be a characteristic experience also in term of usefulness not only as a sort of herbal museum as classical botanical gardens usually are, but also as a living source of plant medicines for the treatment of the diseases, and as a supplier of seedlings for re-forestation actions. Both activities are part of the overall 25 years' research achievements of the Center, which are still constantly improved with the aim to increase and widespread the positive effect on human and nature health.

Takiwasi Botanical Garden represents therefore an important link that joins together the two main areas of work of the Center: therapy and research. At the same time, it is a privileged location for ecology education programs and events directed to local and international visitors. Takiwasi offers tours into its garden of approximately 1 hour with explanations about Amazonian medicinal plants, focused particularly on their practical use in the Center. Among regular visitors we find groups of high-school and college students. The tour is an opportunity to raise awareness on the importance of biodiversity and highlight the problems of loss of species diversity and disappearance of ancestral knowledge related to them that the destruction of Amazonian ecosystems entails. The Center is currently trying to implement, through its fundraising activities, a new botanical garden of medicinal plants within the Botanical Reserve of 54 detached hectares. This would be achieved by conserving, valorizing and putting in evidence the plants that are already present in the area, avoiding any possible ecological foot printing.

\section{Acknowledgments}

None.

\section{Conflict of interest}

Authors declare that their is no conflicto of interest.

\section{References}

1. Giove R. La Liana de los Muertos al Rescate de la Vida, 7 años de experiencia del Centro Takiwasi. Takiwasi;2002:219.

2. Jauregui X, Clavo ZM, Jovel EM, et al. Plantas con madre: plants that teach and guide in the shamanic initiation process in the East-Central Peruvian Amazon. J Ethnopharmacol.2011;134(3):739-752.

3. Sanz Biset J, Cannigueral S. Plant use in the medicinal practices known as "strict diets" in Chazuta valley (Peruvian Amazon). $J$ Ethnopharmacol. 2011;137(1):271-288.

4. Torres J. Memorias del Segundo Foro Internacional Sobre Espiritualidad Indígena. Takiwasi;2002:58-62.

5. Costa L, Fausto C. The Return of the Animists. Recent Studies of Amazonian Ontologies. Religion and Society: Advances in Research. 2010;1:89-109.

6. Daly Lewis. What Kind of People are Plants? The challenges of researching human-plant relations in Amazonia Guyana. AAA. 2015.

7. Frecska E, Bokor P, Winkelman M. The Therapeutic Potentials of Ayahuasca: Possible Effects against Various Diseases of Civilization. Front Pharmacol. 2016;7:35. 